\title{
Leptin promotes the immune escape of lung cancer by inducing proinflammatory cytokines and resistance to apoptosis
}

\author{
YIHONG SHEN, QING WANG, QIONG ZHAO and JIANYING ZHOU \\ Department of Respiratory Diseases, The First Affiliated Hospital, College of Medicine, \\ Zhejiang University, Hangzhou 310003, P.R. China
}

Received August 18, 2008; Accepted December 10, 2008

DOI: 10.3892/mmr_00000099

\begin{abstract}
A growing body of evidence suggests that chronic inflammation contributes to cancer development and progression. Tumor-derived immunoinflammatory cytokines help tumor cells escape immune control and limit the success of immunotherapy. Leptin has been proven to promote cancer progression by inducing cancer cell proliferation and invasion. However, the proinflammatory effects of leptin on lung cancer cells have not yet been fully elucidated. In this study, we demonstrated that human lung cancer A549 and H157 cells express leptin receptors $\mathrm{Ob}-\mathrm{Ra}$ and $\mathrm{Ob}-\mathrm{Rb}$, and that leptin stimulation increases the production of immunoinflammatory cytokines: vascular endothelial growth factor (VEGF), interleukin-6 (IL-6) and prostaglandin (PGE2). Moreover, leptin stimulation activated the JAK/STAT3, PI3K/AKT and MEK1/2 signaling pathways, which contributed to VEGF, IL-6 and PGE2 production. Besides increasing immunoinflammatory cytokines, leptin also protected human lung cancer cells from tumor necrosis factor-related apoptosisinduced ligand-mediated cytotoxic death. Thus, we conclude that leptin promotes the immune escape of lung cancer by inducing proinflammatory cytokines and resistance to apoptosis.
\end{abstract}

\section{Introduction}

Leptin, a product of the $L E P$ gene, is secreted predominantly by the adipose tissues and has attracted much attention since its identification in 1995 (1). Leptin levels are directly propor-

Correspondence to: Dr Jianying Zhou, Department of Respiratory Diseases, The First Affiliated Hospital, College of Medicine, Zhejiang University, 79 Qingchun Road, Hangzhou 310003, P.R. China E-mail: drzjy@163.com

Abbreviations: IL-6, interleukin-6; VEGF, vascular endothelial growth factor; TGF- $\beta$, transforming growth factor- $\beta$; PGE2, prostaglandin; TRAIL, tumor necrosis factor-related apoptosis-induced ligand

Key words: leptin, human lung cancer, immune escape, prostaglandin, vascular endothelial growth factor, transforming growth factor- $\beta$ tional to body fat mass, thus levels are increased in obesity. In addition to inhibiting body weight and stimulating energy expenditure, leptin has a plethora of other biological activities, including the regulation of angiogenesis, bone formation, wound healing, hematopoiesis and fertility (2-6). However, the role of leptin in inflammation remains unclear.

Leptin exerts its actions through its specific receptors, which present in a variety of tissues in several alternatively spliced forms. These can be classified as short, long and secreted. In humans and rodents, two leptin receptor isoforms predominate: the long leptin receptor $(\mathrm{Ob}-\mathrm{Rb})$ and the short leptin receptor isoform (OB-Ra) (7). Ligand binding results in receptor homo-oligomerization and activation of the Janus kinase (JAK). The activated kinase, in turn, phosphorylates itself, as well as several tyrosine residues at the leptin receptor intracellular domain. The phosphorylated tyrosines then become a platform for the recruitment of various signaling proteins. The long isoform, Ob-Rb, has a 302-amino acid intracellular domain and is considered essential and responsible for the principle functions of leptin, which mainly activates the janus kinase/signal transducer and activator of transcription (JAK/STAT), PI3K/AKT and mitogen-activated protein kinase (MAPK) signaling pathways. Ob-Ra contains a truncated intracellular domain and has been shown to participate in signaling through JAK-dependent activation of MAPK, but does not activate JAK/STATs.

Epidemiological studies have shown that leptin and leptin receptor expression levels are associated with increased risk of a variety of cancers, such as prostate $(8,9)$, non-Hodgkin lymphoma (10), breast (11), ovarian (12) and colon (13). The involvement and mechanisms of leptin in cancer development and progression have increasingly attracted attention. Previous reports have described the relevant roles of leptin in cell growth, invasion, migration and angiogenesis, supporting its involvement in cancer development and progression $(3,14,15)$. Recently, a growing body of evidence has linked inflammation with the process of carcinogenesis $(16,17)$.

Lung cancer is the leading cause of cancer-related death worldwide (18) and in the P.R. China (19). A large majority of lung cancer patients are smokers and tobacco consumers, characterized by their chronic inflammatory state (20). Exposure to inhaled antigenic particles induces the immunoinflammatory lung response followed by an expression pattern of cytokines and chemokines, which facilitate tumor immunosuppressive network formation and contribute to tumor progression (21). Previous research has found that 
leptin promotes inflammatory cytokine production $(22,23)$. Since there are higher serum leptin levels in long-term smokers than in healthy individuals (24), we investigated whether elevated leptin participates in the lung cancer immunoinflammatory response, thus further contributing to lung cancer progression.

\section{Materials and methods}

Cells and reagents. Epithelial adenocarcinoma cell lines A549 and $\mathrm{H} 157$ were obtained from ATCC and maintained in RPMI-1640 (Gibco) supplemented with 10\% heat-inactivated fetal bovine serum (Gibco) at $37^{\circ} \mathrm{C}$ in a $5 \% \mathrm{CO}_{2}$ atmosphere. For treatment, cells were seeded at a density of $1 \times 10^{6}$ per 100 -mm tissue culture dish. After $16 \mathrm{~h}$ of serum starvation, the culture media were replaced by serum-free media containing leptin treatments as indicated.

$R T-P C R$. Total cellular RNA was extracted from cancer cells stimulated using TRIzol reagent (Invitrogen, Carlsbad, CA) following the manufacturer's instructions. cDNA was synthesized from $1 \mu \mathrm{g}$ of the total RNA prepared with AMV reverse transcriptase (Promega, Madison, WI) using an oligo $(\mathrm{dT})_{18}$ primer. Primers were designed using the software Primer Premier 5.0 and synthesized by Sangon Inc. (Hangzhou, P.R. China). Those used for PCR amplification were: 5'-TTG TGC CAG TAA TTA TTT CCT CTT-3' and 5'-AGT TGG CAC ATT GGG TTC AT-3' for Ob-Ra (200 bp); 5'-CCA TGA TCA TTT TAT CCC CA-3' and 5'-GTC ACT TAA TAC AAA CAG AAC CC-3' for Ob-Rb (480 bp).

ELISA assay. Human lung cancer A549 and H157 cells $\left(5 \times 10^{5} / \mathrm{ml}\right)$ were cultured serum-starved for $16 \mathrm{~h}$, then stimulated with leptin for $24 \mathrm{~h}$ in the presence or absence of the mitogen-activated protein kinase (MAPK) inhibitor PD098059 (Sigma, St. Louis, MO) at $10 \mu \mathrm{mol} / \mathrm{l}$, the phosphatidylinositol 3-kinase (PI3K) inhibitor LY294002 (Cell Signaling) at $10 \mu \mathrm{mol} / 1$, and the JAK/STAT inhibitor AG490 (Calbiochem, San Diego, CA) at $100 \mu \mathrm{mol} / 1$ for the indicated durations. Culture supernatants were collected and stored at $-80^{\circ} \mathrm{C}$. Cytokines in the supernatants were measured by ELISA (R\&D, Minneapolis, MN) according to the manufacturer's instructions.

Western blot analysis. The human lung cancer A549 and H157 cells $\left(5 \times 10^{5} / \mathrm{ml}\right)$ were stimulated with leptin at different time intervals as indicated. Cells were lysed with M-PER ${ }^{\mathrm{TM}}$ Protein Extraction Reagent (Pierce, Rockford, IL) supplemented with protease inhibitor cocktail. After centrifugation at $13000 \mathrm{x} \mathrm{g}$ at $4^{\circ} \mathrm{C}$ for $15 \mathrm{~min}$, the supernatants were collected. The protein concentration of the extracts was measured by BCA protein assay (Pierce) according to the manufacturer's instructions. Protein $(30 \mu \mathrm{g})$ was loaded onto $10 \%$ SDS-polyacrylamide gels, transferred onto nitrocellulose membranes, and then blotted as previously described. Blots were incubated overnight in a cold room with the indicated antibody (1:500) and subsequently with HRP-conjugated antibody for $1 \mathrm{~h}$. Antibodies for the short and long forms of leptin receptor Ob-R (H-300) were purchased from Santa Cruz Biotechnology Inc. (Santa Cruz, CA). Antibodies for phosphorylated extracellular signalregulated kinase (pERK-Thr202/Tyr204), phosphorylated
A

B
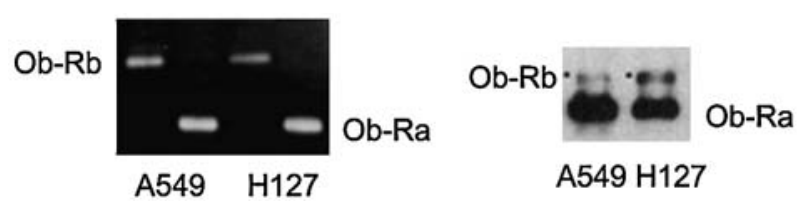

Figure 1. Expression of leptin receptors in A549 and H157 cells. Two types of leptin receptors, Ob-Rb and Ob-Ra, were analyzed by (A) RT-PCR and (B) Western blot analysis according to the detailed protocol described in Materials and methods.

STAT3 (pSTAT-Tyr705) and phosphorylated AKT (pAKTSer473) were purchased from Cell Signaling (Beverly, MA). Antibodies for ERK, STAT3, AKT and actin were purchased from Santa Cruz Biotechnology Inc.

Analysis of cellular apoptosis. Apoptosis was analyzed by FACS as previously described. Lung cancer A549 and H157 cells $\left(5 \times 10^{5} / \mathrm{ml}\right)$ were treated with tumor necrosis factorrelated apoptosis-induced ligand (TRAIL) $(500 \mathrm{ng} / \mathrm{ml})$ for $24 \mathrm{~h}$ in the presence or absence of leptin. Cells were harvested and washed in PBS, resuspended in pre-diluted binding buffer and stained with Annexin V-FITC and PI (BD Pharmingen) for $15 \mathrm{~min}$ at room temperature, protected from light. Cells were then washed and resuspended in PI binding buffer, and the apoptosis of cells was analyzed immediately by flow cytometry using Cell Quest Software.

Statistical analysis. Data were represented as the mean \pm standard deviation (SD) of more than three separate experiments performed in triplicate. Statistical analysis was performed using the Student's t-test. P-values $<0.05$ were considered to be significant.

\section{Results}

Leptin receptors are expressed in A549 and H157 cells. Leptin exerts its biological functions by binding to its receptors, thus mediating a downstream signal by activating multiple signaling pathways. We first examined the expression of leptin receptors in A549 and H157 cells. The mRNA expression of the long $(\mathrm{Ob}-\mathrm{Rb})$ and short $(\mathrm{Ob}-\mathrm{Ra})$ leptin receptor variants in A549 and $\mathrm{H} 157$ cells was detected by reverse transcription-PCR using specific primers described in Materials and methods. The mRNA band for the long isoform was less prominent than the bands for the short isoform (Fig. 1A). Protein expression of the leptin receptors was further confirmed by immunoblotting assay using antibody H300, which identified both Ob-Ra and Ob-Rb (Fig. 1B).

Leptin promotes immunoinflammatory cytokines in human lung cancer cells. Initiation of the immunoinflammatory lung response is induced by exposure to inhaled antigenic particles and is followed by an expression pattern of immunoinflammatory cytokines $(25,26)$. Leptin is known to be upregulated upon sustained smoke exposure (24). In order to investigate the proinflammatory role of leptin signaling in lung cancer cells, we detected the immunoinflammatory cytokines VEGF, 

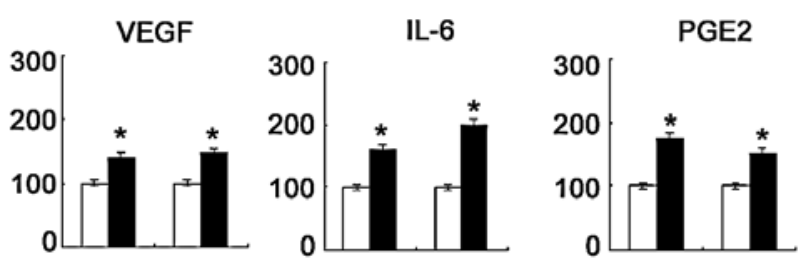

Figure 2. Leptin induces the increased production of VEGF, IL-6 and PGE2 in human lung cancer cells. Human lung cancer A549 and H157 cells $\left(5 \times 10^{5} / \mathrm{ml}\right)$ were cultured serum-starved for $16 \mathrm{~h}$ then stimulated with leptin $(100 \mathrm{ng} / \mathrm{ml})$ for $24 \mathrm{~h}$. Expression of immunoinflammatory cytokines in the cell-free supernatants, including IL-6, VEGF and PGE2, was determined by ELISA and expressed as a percent of the basal level (vehicle-treated) in response to leptin treatments. Values are the means \pm SD of three independent experiments. ${ }^{*} \mathrm{p}<0.05$ compared with leptin-untreated group.
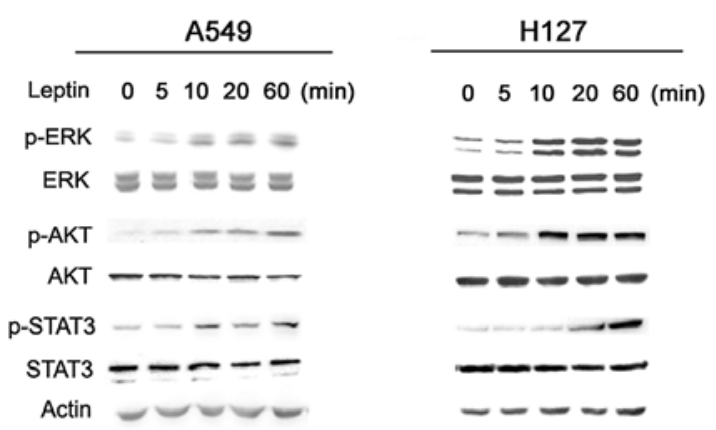

Figure 3. Leptin induces activation of the ERK, PI3/AKT and JAK/STAT3 pathways in lung cancer cells. A549 and H157 cells were cultured serumstarved for $16 \mathrm{~h}$ and treated with leptin $(100 \mathrm{ng} / \mathrm{ml})$ at various time intervals Time 0 represents the absence of leptin or untreated cells. Cell lysates were prepared and run in $8 \%$ SDS-PAGE gel, followed by immunoassy with specific phosphorylation antibody for ERK1/2, AKT and STAT3. Loading proteins were quantified by antibody for the corresponding protein and $ß$-actin.

TGF-3, IL-10, PGE2 and IL-6 following leptin stimulation. No significant difference in IL-10 and TGF- 3 expression was found (data not shown). As shown in Fig. 2, $100 \mathrm{ng} / \mathrm{ml}$ leptin significantly promoted the expression of VEGF, IL-6 and PGE2 expression in the A549 and H157 cells.

Leptin activates the ERK, AKT and STAT3 signaling pathways. To gain insight into the mechanism underlying the proinflammatory effect of leptin on lung cancer cells, we examined the changes in signal transduction pathways plausibly involved in mediating leptin action, including ERK1/2, PI3K/AKT and JAK/STAT3 (27). Stimulation of A549 and H157 cells with leptin led to an immediate increase in ERK1/2 phosphorylation. Similarly, leptin significantly and immediately increased the phosphorylation of AKT and STAT3 (Fig. 3).

Activation of ERK, AKT and STAT3 is responsible for leptininduced immunoinflammatory factors. We next attempted to determine which activated signaling pathway mediated the increased immunoinflammatory cytokine production. A549 or H157 cells were pre-incubated with the MEK1/2 signaling inhibitor PD098059, PI3K/AKT signaling inhibitor LY294002 or JAK2/STAT3 inhibitor AG490 for $30 \mathrm{~min}$, Subsequently, VEGF, IL-6 and PGE2 expression was determined after stimulation with leptin for $24 \mathrm{~h}$. As shown in Fig. 4, leptin-induced VEGF expression was significantly abrogated by LY294002
A

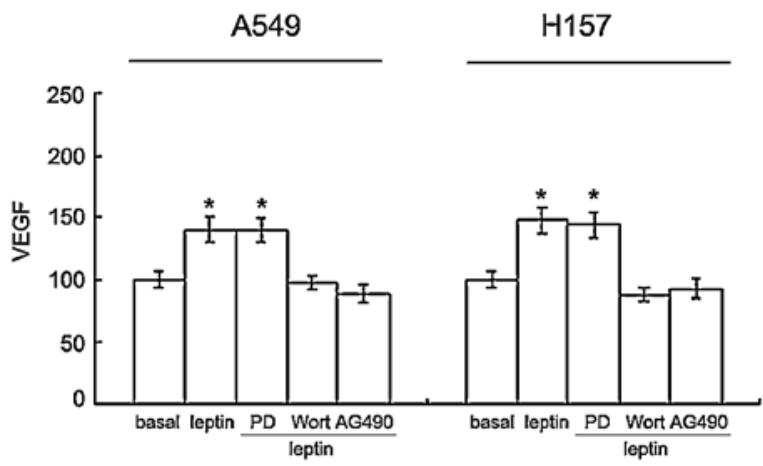

B

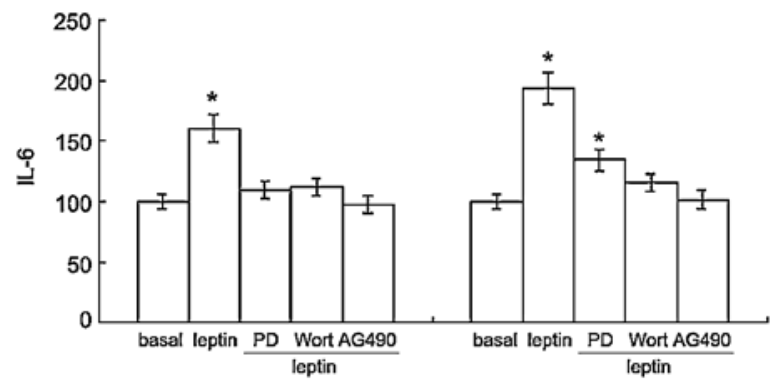

C

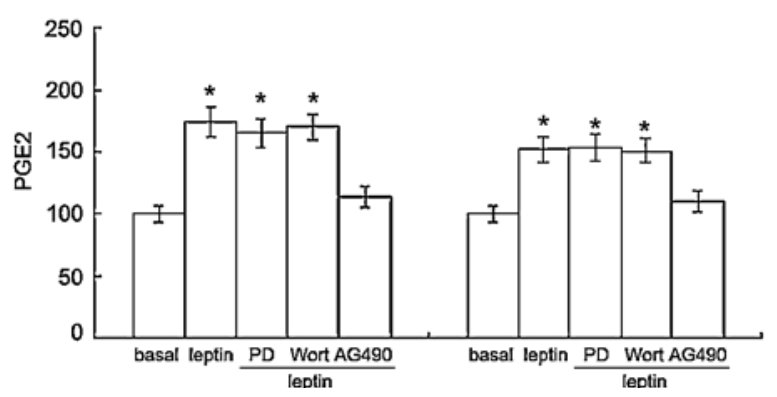

Figure 4. Leptin failed to increase the secretion of VEGF, IL-6 and PGE2 in the presence of ERK, PI3/AKT and JAK/Stat inhibitor. A549 and H157 cells were cultured, serum-starved for $16 \mathrm{~h}$ and pre-treated with $10 \mu \mathrm{mol} / 1$ ERK inhibitor PD98059 (PD), $10 \mu \mathrm{mol} / 1 \mathrm{PI} 3 \mathrm{~K} / \mathrm{AKT}$ LY294002 (Wort) and $100 \mu \mathrm{mol} / 1 \mathrm{JAK} /$ Stat inhibitor (AG490) for $45 \mathrm{~min}$, followed by $100 \mathrm{ng} / \mathrm{ml}$ leptin stimulation. VEGF (A), IL-6 (B) and PGE2 (C) in the cell culture supernatants were assayed using sandwich ELISA. Values are the means \pm SD of three independent experiments. " $\mathrm{p}<0.05$ compared with leptin stimulation alone.

and AG490, and PGE2 expression was abolished by AG490. IL-6 expression was abolished by all three signaling inhibitors, PD098059, LY294002 and AG490.

Leptin protects human lung cancer cells from TRAIL-induced apoptosis. Leptin can promote tumor immune escape by inducing immunosuppressive cytokine production. We now attempted to determine whether it also protects tumor cells from apoptosis. Lung cancer A549 and H157 cells were preincubated with $100 \mathrm{ng} / \mathrm{ml}$ leptin, and cell apoptosis was analyzed upon TRAIL stimulation. As shown in Fig. 5, leptin was found to protect lung cancer cells from TRAIL-induced apoptosis, suggesting that it also protects them from host immunity attack. A previous study reported that PGE2 facilitated tumor cell survival (28). To determine whether leptininduced PGE2 contributed to lung cancer survival, we preincubated human lung cancer cells with the COX2 inhibitors indomethacin (Indo, $10 \mu \mathrm{mol} / \mathrm{l})$ and NS398 (5 $\mu \mathrm{mol} / \mathrm{l})$ prior 


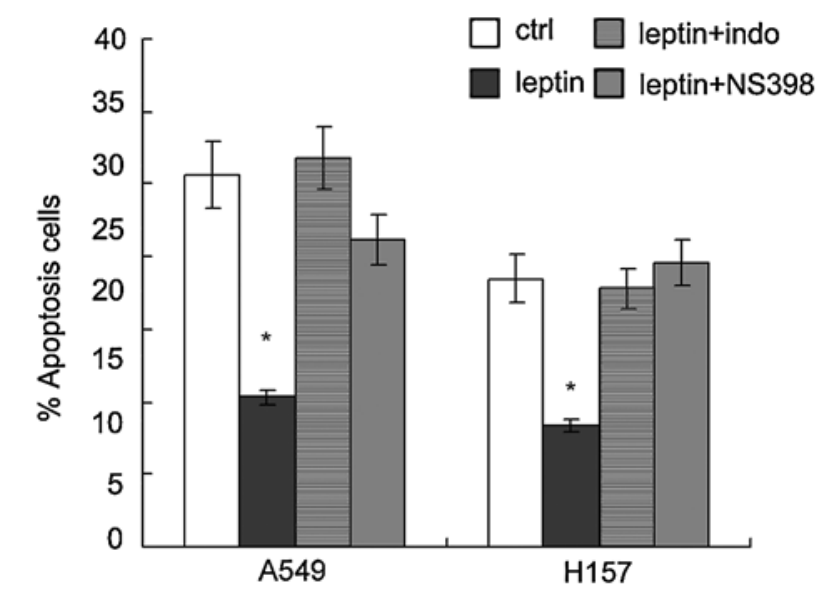

Figure 5. PGE2 contributes to leptin-induced apoptotic resistance of lung cancer cells to TRAIL treatment. A549 cells were pre-treated with $100 \mathrm{ng}$ / $\mathrm{ml}$ leptin for $2 \mathrm{~h}$ prior to treatment with TRAIL $(50 \mathrm{ng} / \mathrm{ml})$ for $24 \mathrm{~h}$ in the presence or absence of the COX2 inhibitors indomethacin (Indo, $10 \mu \mathrm{mol} / 1$ ) and NS398. Subsequently, A549 cells were stained with Annexin V and PI, and subjected to the FACS assay. Cellular apoptosis was analysed with CellQuest software. Apoptosis was described as the percentage of the total number of cells that were Annexin V-and PI-double-positive.

to combined stimulation with TRAIL and leptin. The lepinmediated protective effect was found to be reserved, suggesting that increased PGE2 is responsible for lepin-induced resistance to apoptosis.

\section{Discussion}

A recent human genetics study demonstrated that lung cancer occurrence is associated with a gene polymorphism of leptin, a single nucleotide polymorphism (SNP) in the 50 flanking region at the -2548 locus that is associated with $L E P$ gene regulation. AA genotype carriers with higher mRNA expression and serum leptin levels have increased susceptibility to and earlier occurrence of lung cancer (29). Several reports have described a mitogenic effect of leptin on gastric (30), breast (31), colon (32), ovarian (33), prostate (34), endometrial (35) and hepatocellular carcinoma (15). A previous study also demonstrated that leptin stimulation promotes lung cancer proliferation (36). The present results show that leptin participates in lung cancer growth by promoting immunoinflammatory cytokine production, including VEGF, IL-6 and PGE2, and induces resistance to apoptosis.

It has been widely reported that leptin is associated with inflammation. Recent studies demonstrated that leptin expression increased in the bronchial mucosa of chronic obstructive pulmonary disease patients, in association with airway inflammation and airflow obstruction $(37,38)$. Lung cancer is an inflammation-associated disease. Epidemiologic study has proven that inflammation in conjunction with tobacco use can initiate or promote the development of lung cancer. Such results indicate that tumor-derived immunoinflammatory cytokines such as IL-10, VEGF, IL-6, TGF- 3 and PGE2 help tumor cells escape from host immune attack $(39,40)$. Our data show that leptin promotes lung cancer inflammation by increased secretion of VEGF, IL-6 and PGE2. Tumor-derived VEGF acts as a strong chemoattractant that mobilizes immature myeloid cells (iMCs) from the bone marrow into peripheral vessels, which are further recruited to the tumor site (41). Clinical data support that VEGF expression is responsible for systemic and local DC defects in cancer patients (42). In addition, VEGF confers a survival advantage to cancer cells based on its potent role in stimulating angiogenesis. Several clinical reports have highlighted the prognostic importance of IL-6 in a variety of human solid tumors. Besides directly promoting tumor cell proliferation, IL-6 also plays an essential role in tumor suppressive network formation, by inducing DC defects and tumor-associated macrophage formation in tumors $(43,44)$. Cyclooxygenase-2 (COX-2) overexpression is noted in many malignancies, including lung cancer. It has been proven that elevated tumor PGE2 levels are implicated in angiogenesis, tumor growth and invasion, as well as the suppression of anti-tumor immunity (45). In the present study, we also demonstrated that leptin-induced PGE2 mediated leptin-induced apoptotic resistance to TRAIL. Therefore, increased expression of VEGF, IL-6 and PGE2 following leptin activation in human lung cancer cells may contribute to the suppression of the tumor-specific immune response, ultimately leading to tumor escape from immune control.

As a first attempt at elucidating the signaling pathways involved in the leptin-mediated induction of inflammatory cytokines in lung cancer cells, we examined the effect of leptin on the activation of the JAK/STAT-AKT/ERK pathway. In human lung cancer cells, our data clearly indicate that leptin stimulation rapidly induces the phosphorylation of ERK, AKT, JAK2/STAT3, thus activating these key signal transduction pathways associated with immunoinflammatory cytokine production. Importantly, inhibition of these pathways with specific chemical inhibitors decreased leptin-induced inflammatory cytokine production and resistance to apoptosis. Thus, in the present study, it is clear that leptin triggered carcinoma cell-derived inflammatory cytokine production via a pathway involving the JAK/STAT-AKT/ERK axis, as pharmacologic inhibition of this pathway significantly abolished leptininduced immunosuppressive cytokine production and resistance to apoptosis.

We found that, though lung cancer A549 and H157 cells are sensitive to TRAIL-mediated apoptosis, this can be reversed by leptin treatment, and that leptin-induced PGE2 is essential for apoptotic resistance. These results elucidate another molecular mechanism for the leptin-induced immune escape of lung cancer, and demonstrate that i) human lung cancer A549 and H157 cells express leptin receptors Ob-Ra and $\mathrm{Ob}-\mathrm{Rb}$, ii) leptin promotes lung cancer inflammation by inducing VEGF, IL-6 and PGE2 expression, iii) immediate activation of the JAK/STAT3, PI3K/AKT and ERK signaling pathways upon leptin stimulation contributes to increased immunoinflammatory cytokine production, and iv) leptin protects lung cancer cells from TRAIL-mediated apoptosis.

\section{Acknowledgements}

We thank Guohua Luo for expert technical assistance and Dr Hequan Li for the critical reading of the manuscript. This work was supported by the Department of Science and Technology Grant (no. 2005C33013) and the Research Fund for Medical Science (no. 2006B031), Zhejiang province, P.R. China. 


\section{References}

1. MacDougald OA, Hwang CS, Fan H and Lane MD: Regulated expression of the obese gene product (leptin) in white adipose tissue and 3T3-L1 adipocytes. Proc Natl Acad Sci USA 92: 9034-9037, 1995.

2. Huang L and Li C: Leptin: a multifunctional hormone. Cell Res 10: 81-92, 2000 .

3. Sierra-Honigmann MR, Nath AK, Murakami C, Garcia-Cardena G, Papapetropoulos A, Sessa WC, Madge LA, Schechner JS, Schwabb MB, Polverini PJ and Flores-Riveros JR: Biological action of leptin as an angiogenic factor. Science 281: 1683-1686, 1998.

4. Takeda S, Elefteriou F, Levasseur R, Liu X, Zhao L, Parker KL, Armstrong D, Ducy P and Karsenty G: Leptin regulates bone formation via the sympathetic nervous system. Cell 111: 305-317, 2002.

5. Rosenbaum M and Leibel RL: The role of leptin in human physiology. N Engl J Med 341: 913-915, 1999.

6. Lord GM, Matarese G, Howard JK, Baker RJ, Bloom SR and Lechler RI: Leptin modulates the T-cell immune response and reverses starvation-induced immunosuppression. Nature 394: 897-901, 1998.

7. Tartaglia LA: The leptin receptor. J Biol Chem 272: 6093-6096, 1997.

8. Stattin P, Soderberg S, Hallmans G, Bylund A, Kaaks R, Stenman UH, Bergh A and Olsson T: Leptin is associated with increased prostate cancer risk: a nested case-reference study. J Clin Endocrinol Metab 86: 1341-1345, 2001.

9. Kote-Jarai Z, Singh R, Durocher F, Easton D, Edwards SM, Ardern-Jones A, Dearnaley DP, Houlston R, Kirby R and Eeles R: Association between leptin receptor gene polymorphisms and early-onset prostate cancer. BJU Int 92: 109-112, 2003.

10. Skibola CF, Holly EA, Forrest MS, Hubbard A, Bracci PM, Skibola DR, Hegedus C and Smith MT: Body mass index, leptin and leptin receptor polymorphisms, and non-Hodgkin lymphoma. Cancer Epidemiol Biomarkers Prev 13: 779-786, 2004.

11. Snoussi K, Strosberg AD, Bouaouina N, Ben Ahmed S, Helal AN and Chouchane L: Leptin and leptin receptor polymorphisms are associated with increased risk and poor prognosis of breast carcinoma. BMC Cancer 6: 38, 2006.

12. Mor G, Visintin I, Lai Y, Zhao H, Schwartz P, Rutherford T, Yue L, Bray-Ward P and Ward DC: Serum protein markers for early detection of ovarian cancer. Proc Natl Acad Sci USA 102: 7677-7682, 2005.

13. Slattery ML, Wolff RK, Herrick J, Caan BJ and Potter JD: Leptin and leptin receptor genotypes and colon cancer: gene-gene and gene-lifestyle interactions. Int J Cancer 122: 1611-1617, 2008 .

14. Somasundar P, McFadden DW, Hileman SM and Vona-Davis L: Leptin is a growth factor in cancer. J Surg Res 116: 337-349, 2004.

15. Saxena NK, Sharma D, Ding X, Lin S, Marra F, Merlin D and Anania FA: Concomitant activation of the JAK/STAT, PI3K/ AKT, and ERK signaling is involved in leptin-mediated promotion of invasion and migration of hepatocellular carcinoma cells. Cancer Res 67: 2497-2507, 2007

16. Clevers H: At the crossroads of inflammation and cancer. Cell 118: 671-674, 2004

17. Balkwill $\mathrm{F}$ and Coussens LM: Cancer: an inflammatory link. Nature 431: 405-406, 2004.

18. World Health Organization: Preventing chronic disease: a vital investment. World Health Organization (WHO), Geneva, 2005.

19. Yang L, Li L, Chen Y and Parkin D: Cancer incidence and mortality estimates and prediction for year 2000 and 2005 in China. Chin J Health Stat 4: 218-231, 2005.

20. Stayner L, Bena J, Sasco AJ, Smith R, Steenland K, Kreuzer M and Straif K: Lung cancer risk and workplace exposure to environmental tobacco smoke. Am J Public Health 97: 545-551, 2007.

21. Ballaz S and Mulshine JL: The potential contributions of chronic inflammation to lung carcinogenesis. Clin Lung Cancer 5: 46-62, 2003.

22. Ogunwobi O, Mutungi G and Beales IL: Leptin stimulates proliferation and inhibits apoptosis in Barrett's esophageal adenocarcinoma cells by cyclooxygenase-2-dependent, prostaglandinE2-mediated transactivation of the epidermal growth factor receptor and c-Jun NH2-terminal kinase activation. Endocrinology 147: 4505-4516, 2006.
23. Fenton JI, Hursting SD, Perkins SN and Hord NG: Interleukin-6 production induced by leptin treatment promotes cell proliferation in an Apc $\left(\mathrm{Min} /{ }^{+}\right)$colon epithelial cell line. Carcinogenesis 27: 1507-1515, 2006

24. Eliasson B and Smith U: Leptin levels in smokers and long-term users of nicotine gum. Eur J Clin Invest 29: 145-152, 1999.

25. Arenberg D: Chemokines in the biology of lung cancer. J Thorac Oncol 1: 287-288, 2006.

26. Matsumoto K, Aizawa H, Inoue H, Koto H, Takata S, Shigyo M Nakano $\mathrm{H}$ and Hara N: Eosinophilic airway inflammation induced by repeated exposure to cigarette smoke. Eur Respir J 12: 387-394 1998.

27. Fruhbeck G: Intracellular signalling pathways activated by leptin. Biochem J 393: 7-20, 2006.

28. Casado M, Molla B, Roy R, Fernandez-Martinez A, Cucarella C, Mayoral R, Bosca L and Martin-Sanz P: Protection against Fasinduced liver apoptosis in transgenic mice expressing cyclooxygenase 2 in hepatocytes. Hepatology 45: 631-638, 2007

29. Ribeiro R, Araujo AP, Coelho A, Catarino R, Pinto D, Araujo A, Calcada C, Lopes C and Medeiros R: A functional polymorphism in the promoter region of leptin gene increases susceptibility for non-small cell lung cancer. Eur J Cancer 42: 1188-1193, 2006.

30. Pai R, Lin C, Tran T and Tarnawski A: Leptin activates STAT and ERK2 pathways and induces gastric cancer cell proliferation. Biochem Biophys Res Commun 331: 984-992, 2005.

31. Caldefie-Chezet F, Damez M, De Latour M, Konska G, Mishellani F, Fusillier C, Guerry M, Penault-Llorca F, Guillot J and Vasson MP: Leptin: a proliferative factor for breast cancer? Study on human ductal carcinoma. Biochem Biophys Res Commun 334: 737-741, 2005.

32. Melen-Mucha G and Lawnicka H: Leptin promotes the growth of Colon 38 cancer cells and interferes with the cytotoxic effect of fluorouracil in vitro. Endokrynol Pol 58: 2-6, 2007.

33. Choi JH, Park SH, Leung PC and Choi KC: Expression of leptin receptors and potential effects of leptin on the cell growth and activation of mitogen-activated protein kinases in ovarian cancer cells. J Clin Endocrinol Metab 90: 207-210, 2005.

34. Somasundar P, Frankenberry KA, Skinner H, Vedula G, McFadden DW, Riggs D, Jackson B, Vangilder R, Hileman SM and Vona-Davis LC: Prostate cancer cell proliferation is influenced by leptin. J Surg Res 118: 71-82, 2004.

35. Sharma D, Saxena NK, Vertino PM and Anania FA: Leptin promotes the proliferative response and invasiveness in human endometrial cancer cells by activating multiple signal-transduction pathways. Endocr Relat Cancer 13: 629-640, 2006.

36. Tsuchiya T, Shimizu H, Horie T and Mori M: Expression of leptin receptor in lung: leptin as a growth factor. Eur J Pharmacol 365: 273-279, 1999.

37. Bruno A, Chanez P, Chiappara G, Siena L, Giammanco S, Gjomarkaj M, Bonsignore G, Bousquet $\mathrm{J}$ and Vignola AM: Does leptin play a cytokine-like role within the airways of COPD patients? Eur Respir J 26: 398-405, 2005

38. Broekhuizen R, Vernooy JH, Schols AM, Dentener MA and Wouters EF: Leptin as local inflammatory marker in COPD. Respir Med 99: 70-74, 2005.

39. Zou W: Immunosuppressive networks in the tumour environment and their therapeutic relevance. Nat Rev Cancer 5: 263-274, 2005.

40. Kim R, Emi M, Tanabe K and Arihiro K: Tumor-driven evolution of immunosuppressive networks during malignant progression. Cancer Res 66: 5527-5536, 2006.

41. Kusmartsev S and Gabrilovich DI: Immature myeloid cells and cancer-associated immune suppression. Cancer Immunol Immunother 51: 293-298, 2002.

42. Gottfried E, Kreutz M and Mackensen A: Tumor-induced modulation of dendritic cell function. Cytokine Growth Factor Rev 19: 65-77, 2008

43. Ratta M, Fagnoni F, Curti A, Vescovini R, Sansoni P, Oliviero B, Fogli M, Ferri E, Della Cuna,GR, Tura S, Baccarani M and Lemoli RM: Dendritic cells are functionally defective in multiple myeloma: the role of interleukin-6. Blood 100: 230-237, 2002.

44. Duluc D, Delneste Y, Tan F, Moles MP, Grimaud L, Lenoir J, Preisser L, Anegon I, Catala L, Ifrah N, Descamps P, Gamelin E, Gascan H, Hebbar M and Jeannin P: Tumor-associated leukemia inhibitory factor and IL-6 skew monocyte differentiation into tumor-associated macrophage-like cells. Blood 110: 4319-4330, 2007.

45. Krysan K, Reckamp KL, Sharma S and Dubinett SM: The potential and rationale for COX-2 inhibitors in lung cancer. Anticancer Agents Med Chem 6: 209-220, 2006. 